Dr Marianne Reid

School of Nursing,

University of the Free

State, Bloemfontein,

South Africa

(reidm@ufs.ac.za)

ORCID: https://orcid.

org/0000-0002-1074-

1465

DOl: https://dx.doi.

org/10.18820/24150525/

Comm.v24.1

ISSN 2415-0525 (Online)

Communitas 2019 24: 1-20

Date submitted:

30 January 2019

Date accepted:

22 July 2019

Date published:

10 October 2019

(c) Creative Commons With Attribution (CC-BY)
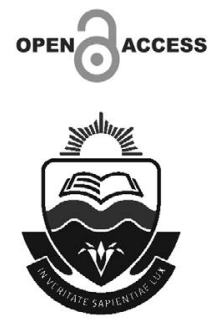

\section{HEALTH DIALOGUE: \\ A CONCEPT ANALYSIS}

\begin{abstract}
Health dialogue encompasses strategies to influence decisions to improve health, but it is often still poorly understood. An analysis assists in creating a definition with a sound theoretical base, promoting consistency in using the concept, and understanding the underlying defining characteristics. The Walker and Avant approach was used to guide this concept analysis. The characteristics of health dialogue include an equal, symbiotic health relationship between the patient and the healthcare provider, and reciprocal health communication towards reaching an identified health goal via a health message. Antecedents include both patient and healthcare provider presenting with a positive attitude towards health dialogue, displaying sensitivity towards cultural, contextual and societal factors, and receiving training on health matters and communication skills. The consequence is an improved health outcome. Empirical referents comprise sharing an understanding of responsibility/decision-making, establishing a health plan, applying context-sensitive health communication strategies, and declaring mutual benefits received from the health relationship. This concept analysis serves to clarify the concept within theory development and research. The defined characteristics further afford healthcare providers ways to measure the concept in their work environment and encourage health communication.
\end{abstract}

Keywords: health communication; health dialogue; health message; concept analysis; Walker and Avant approach; participatory communication; participatory paradigm; transactional communication

\section{INTRODUCTION}

This article reports on an analysis of the concept "health dialogue". The research argues for the implementation of said concept to replace the currently popular collection of terms such as "health communication" and "health education". Patienthealthcare provider interaction and academic research is in need of a more distinct, patient-friendly and positive concept to use in the health discipline. 


\section{BACKGROUND AND PROBLEM STATEMENT}

Health concepts that encompass psychosocial and behavioural phenomena are abstract and not observable or measurable. Such concepts should be researched by means of a concept analysis in order to assure mutual comprehension, interpretation and general cognition among scholars and academics in view of conducting valid and reliable research as well as effective health interventions (Alligood 2014; Bousso et al. 2013). Scholarly cognition of a concept is distinguished from everyday subjective meanings. The use of multiple terms to describe one specific concept leads to confusion and disarray in patient interaction and research.

A basic feature of health practice interventions includes the "conversation" between healthcare worker and patient. This interaction is generally referred to as "health communication" (Munodwafa 2008; Rimer \& Kreuter 2006) and its alternatives, including health promotion, counselling or health education. These concepts have become challenging as they are experienced by patients as implying that they play subservient and passive roles in the relationship (Schöpf et al. 2017). These terms could imbue the caregiver-patient relationship with negative attitudes, which could lead to non-compliance of health interventions. Consequently, the academic community has sought to use the more recently coined term "health dialogue" to describe patienthealthcare provider interaction.

The term "health dialogue" implies patient engagement and participation in the process of providing health information and knowledge. This fits well with the greater realisation of the complexity of cultural and ethnic diversity that exists within the relationship with patients.

It is within the participatory paradigm, strongly influenced by theorists such as Paulo Freire, that dialogue is presented as a "two-way, interactive and participatory" process (Tomaselli 2011). Freire's understanding of dialogue embraces communication between people in an equal relationship, with critical-thinking and self-realisation taking prominence. During the process, great value is placed on aspects such as mutual respect, humility and trust (Rule 2011). Dialogue within this paradigm is based on the sharing of knowledge, rather than a top-down linear approach from an "informed" source to a "passive" receiver. The transactional nature of the dialogue process between two or more people takes centre stage, creating the platform to work towards a healthy population (Corcoran 2013; Tubbs et al. 2012).

Health interaction occurs in different settings (Tubbs et al. 2012). The concept analysis offered in this article pertains to interpersonal, small-group and mass interface scenarios. The focus of data gathering and analysis is on adult and intercultural research of different texts. The problem this research seeks to address is conceptualising the concept "health dialogue", promoting consistency whenever the concept is used. Likewise, the research ascertains whether the concept "health dialogue" meets the requirements of endorsing the validity and reliability of the research. Nuopponen (2010) maintains that the creation of conceptual clarity is of importance for all kinds of research. 


\section{RESEARCH DESIGN}

The concept analysis of "health dialogue" was conducted researching a large quantity of applicable literature. The study is underpinned by a participatory paradigm and employs the concept analysis model of Walker and Avant (2011), which is often used in health research (Nuopponen 2010). By executing this model, the structure and function of the concept is determined as well as the potential benefits of establishing the concept within healthcare. This simplified classic concept analysis modified by Walker and Avant (2011) involves eight steps used as an iterative process, namely

1. selecting the concept;

2. determining the purpose of the analysis;

3. identifying all possible uses of the concept;

4. determining the key characteristics;

5. identifying a model case;

6. constructing a borderline and contrary case;

7. identifying the antecedents and consequences; and

8. keying the empirical referents.

\section{DATA COLLECTION}

\section{Data gathering according to a multi-stage strategy}

Sources for the concept analysis were sought in a series of stages (see Table 1), with the assistance of a co-data analyst and librarian. Stage one identified hard and electronic copies of dictionaries from the Credo Reference database $(N=792)$. After including only English explanatory dictionaries referring to individual use or combinations of the terms "health" and "dialogue" within any context and thereafter removing non-explanatory, non-English and duplicate dictionaries or dictionaries not referring to individual use or combinations of the terms "health" and "dialogue", the final selection of dictionaries $(n=143)$ was concluded.

Various explanatory dictionaries repeated the same definition of either "health" or "dialogue". A developed data extraction form assisted the researchers in copying the unique definitions of health $(n=62)$ and of dialogue $(n=40)$, excluding repetitive definitions. The data extraction form further assisted in reflecting all repetitive words from dictionaries, which allowed the compilation of a search string used during stage two.

The search string was used in stage three to identify abstracts $(N=1570)$ from the EBSCOhost interface, specifically targeting adult patients in health dialogue with healthcare providers. The health dialogue could have taken place in either an interpersonal, small group or mass communication context. Health dialogue amongst healthcare providers were excluded, and duplicate abstracts were manually removed, determining the final list of abstracts $(n=1154)$. 
Stage four presented the opportunity to identify articles $(\mathrm{N}=324)$ from abstracts also using the EBSCOhost interface. The same inclusion and exclusion criteria applicable to abstracts applied to article identification $(n=147)$. The article search was further limited to available copies, scholarly publications with a length of more than one page, and English publications between 2000 and 2013. Duplicate copies were removed manually and book reviews were excluded.

The multi-stage search strategy directed researchers to review the identified articles, which facilitated identification of the key characteristics of health dialogue that occurred repeatedly, deepening insight into the concept. In summary, the characteristics of health dialogue include an equal, symbiotic health relationship between the patient and the healthcare provider.

\section{TABLE 1: MULTI-STAGE SEARCH STRATEGY}

\begin{tabular}{|c|c|c|}
\hline Stage & Resources & Sources \\
\hline \multirow[t]{2}{*}{ Stage 1} & $\begin{array}{l}\text { Electronic/hard copy } \\
\text { dictionaries: } \\
\text { Identified }(\mathrm{N}=792) \\
\text { Used }(\mathrm{n}=143)\end{array}$ & \multirow{2}{*}{$\begin{array}{l}\text { Source: Credo Reference database (Credo Reference } \\
\text { is a commercial database containing full-text reference } \\
\text { e-books. Currently it contains about } 3507788 \text { full } \\
\text { text entries in } 742 \text { reference books (dictionaries and } \\
\text { encyclopaedias, both general and subject specific). } \\
\text { It is available through subscription from http://search. } \\
\text { credoreference.com/ An advanced search option is } \\
\text { available, allowing users to search within headings, } \\
\text { resulting in relevant results.) }\end{array}$} \\
\hline & $\begin{array}{l}\text { Dictionaries }(n=143) \\
\text { with usable concepts } \\
\text { describing: } \\
\text { Health }(n=62) \\
\text { Dialogue }(n=40)\end{array}$ & \\
\hline Stage 2 & $\begin{array}{l}\text { Search strings } \\
\text { compiled }\end{array}$ & 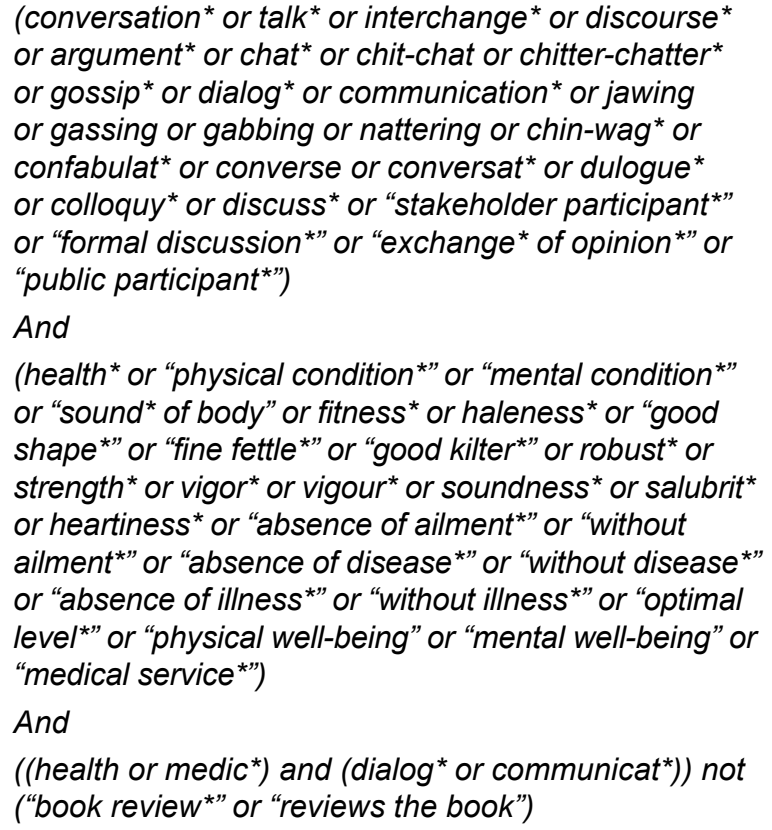 \\
\hline
\end{tabular}




\begin{tabular}{|c|c|c|}
\hline Stage & Resources & Sources \\
\hline Stage 3 & $\begin{array}{l}\text { Abstracts } \\
\text { Identified }(N=1570) \\
\text { Used }(n=1 \text { 154) }\end{array}$ & $\begin{array}{l}\text { Source: EBSCOhost interface } \\
\text { (Academic Search Complete, Africa-Wide Information, } \\
\text { AHFS Consumer Medication Information, CINAHL } \\
\text { with Full Text, ERIC, Health Source - Consumer } \\
\text { Edition, Health Source: Nursing/Academic Edition, } \\
\text { MEDLINE with Full Text, PsycARTICLES, PsycINFO, } \\
\text { SocINDEX with Full Text, SPORTDiscus with Full Text, } \\
\text { Communication \& Mass Media Complete, Humanities } \\
\text { Source, MasterFILE Premier) }\end{array}$ \\
\hline Stage 4 & $\begin{array}{l}\text { Articles } \\
\text { Identified }(N=324) \\
\text { Used }(n=147)\end{array}$ & $\begin{array}{l}\text { Source: EBSCOhost interface (Academic Search } \\
\text { Complete, Africa-Wide Information, AHFS Consumer } \\
\text { Medication Information, CINAHL with Full Text, ERIC, } \\
\text { Health Source - Consumer Edition, Health Source: } \\
\text { Nursing/Academic Edition, MEDLINE with Full Text, } \\
\text { PsycARTICLES, PsycINFO, SocINDEX with Full } \\
\text { Text, SPORTDiscus with Full Text, Communication } \\
\text { \& Mass Media Complete, Humanities Source, } \\
\text { MasterFILE Premier) }\end{array}$ \\
\hline
\end{tabular}

\section{Rigour}

This concept analysis, guided by Walker and Avant's (2011) framework for performing a concept analysis, assisted the researchers to be meticulous throughout all the stages of the analysis. An audit trial of each stage of the analysis was kept. The iterative nature of a concept analysis, as well as consensus discussions between involved researchers, further strengthened the rigour of the reported research.

\section{RESULTS OF THE LITERATURE REVIEW}

The literature review informed the stages of the analysis model as suggested by Walker and Avant (2011).

\section{Stage one: selecting the concept}

The concept "health dialogue" was selected for analysis because it is nominated to become the term that emphasises the reciprocal relationship between healthcare provider and patient in the clinical setting.

In the discipline of nursing, "health communication" is used interchangeably with the terms "health education" (Han et al. 2009; McMillan et al. 2008), "health promotion" (Kemppainen et al. 2012; DuBenske et al. 2010), "counselling" (Gessler et al. 2012; Bradley et al. 2011), and "health information" (Goodall et al. 2010). All these concepts denote the patient as being merely the receiver of education, information, advice or knowledge. There is a suggestive notion of an unequal partnership between healthcare provider and patient. 
According to Munodwafa (2008), "Health communication seeks to increase knowledge gain. This is the minimum expectation and acceptable requirement to demonstrate that learning has taken place following an intervention using communication". The focus here is on mere knowledge gain, which is not a reciprocal action.

Rimer and Kreuter (2006) and Longtin et al. (2010) also negate participatory pedagogy when they adopt the general stance that health interaction and conversations should comprise the offering of information and behaviour change strategies related to positive health outcomes of interest to the patient as derived from individual assessment. The authors maintain that researchers should "identify key leverage points for impact on such intermediate outcomes as persuasion and yielding" and that "patient participation is increasingly recognised as a key component in the redesign of healthcare processes". These references clearly convey the submissive stance of the patient when interacting with a healthcare provider.

The author's 20 years of clinical experience in the primary healthcare setting resulted in an awareness that healthcare providers tend to revert to a top-down linear approach in their relations with a patient. Although it is observed that the intention of healthcare providers appears to advocate patient empowerment and self-management, the knowledge base of healthcare providers when employing this approach seems vague. The impression exists that they do not have a grasp of the terminology and its application.

The use of multiple terms to describe one specific concept leads to confusion in patient interaction and research. The concept "health dialogue" presents a modernistic portrayal of the caregiver-client interaction. Acknowledgement, recognition and respect for the client as an equal is implied by the term. The author's clinical and academic background has been strongly influenced by the position taken by participatory pedagogy in choosing the concept "health dialogue"; especially as, within the stated participatory paradigm of this study, the concept "health dialogue" takes a much stronger interactive position than concepts such as "health education" or "health promotion", which has a suggestive notion of an unequal partnership between healthcare provider and patient.

\section{Stage two: determining the purpose of the analysis}

The purpose of the analysis is to determine how lexical evidence as derived from dictionaries and obtained from articles informs the concept "health dialogue" as it pertains to the reciprocal sharing of knowledge, experience, understanding, feelings and practices between the healthcare provider and the patient. The data obtained from the literature search should authenticate the concept in order to validate research.

\section{Stage three: identifying all possible uses of the concepts 'health' and 'dialogue'}

Health

Within a health setting, dictionaries refer to "health" as a state of being free from illness or injury, both physical and mental (White 2006). The sense of well-being accompanied by being healthy is not merely limited to the absence of disease or other abnormal conditions (Hornby 2010). Health is also described as a wish expressed for a person's 
welfare, a toast drunk in a person's honour. Furthermore, health could be seen as enabling a person to face crises competently and so fulfill social roles (White 2006).

\section{Dialogue}

Dialogue is most often used to denote a conversation between two or more people (Stevenson \& Waite 2011; Cresswell 2010). The conversation forming part of the dialogue is often directed towards the exploration of a particular subject or the resolution of a problem (Hornby 2010). Dialogue has also been defined as a means of exchange between people of facts and ideas involved in a process of public or stakeholder participation (Schiavo 2014; Cowan 2005). The conversation can be presented orally as part of a formal discussion or in written form, such as conversations in a book, play or film (Stevenson 2010).

\section{Stage four: the key characteristics of health dialogue}

\section{Equal, symbiotic health relationship}

An effective healthcare provider-patient relationship is characterised by shared decision-making and common expectations (Hornby 2010). Such a relationship is found when both role players agree to be equal partners in a health relationship; thus, leading to reaching a health goal dependent on the input of both parties. Healthcare providers could be challenged to acknowledge the patient as an expert on how to lead his/her own life, whilst simultaneously adding his/her own expert knowledge to the discussion (Coulter et al. 2008; Vivian \& Wilcox 2000). Despite the challenges faced, such collaboration and participation can be effective in various healthcare situations and can be fruitfully utilised in various contexts, especially when healthcare providers use innovative approaches to strive towards a relationship where the patient is acknowledged as an equal partner.

\section{Reciprocal health communication}

Reciprocal communication is only possible when patients become full participants in their own healthcare. Such participation is likely when healthcare providers follow a patient-centred perspective and patients follow a proactive approach by communicating about their health with healthcare providers (Neuhauser et al. 2009). Such a twoway process would allow both patients and healthcare providers to work towards early diagnosis and effective treatment of an illness as well as patient empowerment (Osterlund et al. 2009; Butow et al. 2007).

\section{Health message}

Health messages can combine various communication strategies to be used in different contexts (Kreps \& Sivaram 2008; Bernhardt 2004). Such health messages should be audience-specific (Varma et al. 2010) and could be presented as an online chat group (Donelle \& Hoffman-Goetz 2009) or in a face-to-face engagement between patients and healthcare providers (Harvey \& O'Brien 2011; Petts \& Niemeyer 2004). Using multiple strategies when catering for the unique needs of patients may consolidate learning and recall in contexts where the behaviour is to be performed (Briscoe \& Aboud 2012). 


\section{Stage five: identifying a model case}

Model, borderline and contrary case examples, as suggested by Walker and Avant (2011), are presented.

\section{Model case}

Walker and Avant (2011) suggest a model case to act as an example demonstrating all key characteristics of the concept. Thus, the identified three key characteristics of the concept health dialogue are presented in the following constructed example as a model case, implying that all three key characteristics are present.

Mrs N, a non-English-speaking patient diagnosed with diabetes regularly visits her healthcare provider for her scheduled follow-up appointments. Her established relationship with her healthcare provider is based on their shared understanding of their respective roles and responsibilities, allowing both parties to bring their own knowledge to the table. After various discussions, they have decided how to manage her blood glucose levels in order to stabilise it at $5 \mathrm{mmol} / \ell$. Mrs $\mathrm{N}$ is thankful that her healthcare provider addresses her in her own language in a manner she understands. She expresses her satisfaction with her ability to improve her blood glucose levels, whereas the healthcare provider expresses satisfaction with Mrs N's positive report of the Patient Opinion Survey, which emphasises their positive healthcare relationship.

An equal healthcare relationship exists between Mrs $\mathrm{N}$ and the healthcare provider, as evidenced by their shared understanding of their respective roles and health responsibilities. Furthermore, the relationship is symbiotic in nature, as declared by both parties in the healthcare relationship. The win-win situation culminates in the Patient Opinion Survey, with the patient reporting positively on the dialogue/care received and therefore the healthcare provider experiences having provided good care. Reciprocal health communication takes place between Mrs $\mathrm{N}$ and her healthcare provider as they have established a collaborative healthcare plan, clearly identifying who is to do what, to reach a specific aim - in this case, a stabilised blood glucose level. The health message takes place within an interpersonal context, whilst being patient-sensitive, as Mrs $\mathrm{N}$ is addressed in her own language at a level acceptable to her.

\section{Stage six: constructing a borderline and contrary case}

\section{Borderline case}

A borderline case contains most of the key characteristics, but not all of them (Walker \& Avant 2011). A constructed example of such a case is the following. Mr B, a teacher and known hypertension patient, visits his healthcare clinic to collect his repeat prescription. His complaints of constant headaches and dizziness lead the healthcare provider to provide Mr B with an information leaflet on hypertension management. No further discussion takes place between Mr B and the healthcare provider. Despite being satisfied with receiving treatment and information about his hypertension, $\mathrm{Mr} B$ still struggles to control his blood pressure. The healthcare provider is satisfied with the quality of healthcare provided to $\mathrm{Mr} \mathrm{B}$. 
Although a health relationship exists between Mr B and the healthcare provider, the relationship is not equal, a there is no shared understanding of their respective roles and health responsibilities. It appears as if the healthcare provider sees her role as mainly providing repeat prescriptions and health related literature. She expects $\mathrm{Mr} B$ to collect the prescription. As both $\mathrm{Mr} \mathrm{B}$ and the healthcare provider are satisfied with the health relationship, a seemingly symbiotic health relationship exists. No reciprocal health communication occurs between $\mathrm{Mr} \mathrm{B}$ and his healthcare provider, as no discussions concerning a health plan/goal takes place. The use of an information leaflet to convey a health message to a literate man such as Mr B demonstrates a degree of patient-context sensitivity, as the healthcare provider may assume Mr B to understand the supplied health related literature. However, such an assumption could be wrong.

\section{Contrary case}

A contrary case acts as an example of "what the concept is not" (Walker \& Avant 2011). A tongue-in-cheek example of a contrary case is a book in Afrikaans, addressing antenatal care exercises, which is displayed in an empty waiting room for African geriatric patients.

No equal healthcare relationship exists because no patient or healthcare provider is present. No symbiosis in a healthcare relationship is, possible without participants. Therefore, reciprocal health communication cannot take place. The Afrikaans book could be used to convey a health message, but it is not context-sensitive, as evidenced by the language medium of the book as well as by antenatal care exercises being an inappropriate topic for geriatric patients. This case is a clear example of what the concept "health dialogue" is not.

\section{Stage seven: identifying the antecedents and consequences}

\section{Antecedents}

In refining the social context in which health dialogue takes place, it is also important to identify events/incidents that need to occur prior to the occurrence of health dialogue. Literature searches assisted in identifying the following antecedents: the patient and healthcare provider should have a positive attitude towards health dialogue; sensitivity is displayed towards cultural, contextual and societal factors; and training has been received on health matters and communication skills. Within a participatory paradigm, identified antecedents are applicable to both the healthcare provider and patient.

\section{- Positive attitude}

A positive attitude towards the health dialogue requires of both the patient and healthcare provider to be open towards creating a platform for collaborative interaction with all the identified role players and so move towards a shared understanding of responsibility and decision-making (Street Jnr et al. 2009). Following a holistic approach, the dignity of all is to be acknowledged (Neuhauser et al. 2009). A positive attitude will further be fostered within a relationship portraying a shared understanding of responsibility, whilst the following relationship characteristics are present: trust, empathy, confirmation and emotional support (Castro et al. 2010). 
- Sensitivity/Respect

It is essential to be sensitive and to show mutual respect towards the culture, belief system and socio-economic milieu in which health dialogue takes place (Taylor et al. 2013; Degni et al. 2012; Kalbfleisch 2009). Acknowledging existing health knowledge, linguistic difficulties and technological skills, as well as the availability of technological devices, are further aspects that require sensitivity prior to engaging in the health dialogue (Suggs \& Mclntyre 2009; Vahabi 2007). Another way in which respect can be shown towards the patient within a health communication encounter is by emphasising tailored health messages (Harvey \& O'Brien 2011; Hinchliff et al. 2005). Combining various communication strategies (Briscoe \& Aboud 2012; Lapinski et al. 2009) has also proven beneficial.

- Training

Healthcare providers benefit from training in communication skills, especially if emphasis is placed on cultural sensitivity within the communication process (Malta et al. 2010; Redsell et al. 2010; Durant et al. 2009). This makes the healthcare providers more sensitive towards patients who might not have been exposed to formal communication skills training, but who still bring their indigenous skills to the health communication encounter. Such indigenous skills/knowledge is seen as "training" that the patient has undergone. Communication skills alone would not be of much benefit without healthcare providers who have the necessary knowledge base entering health communication (Savdie \& Chetley 2009), whilst simultaneously acknowledging patients' own knowledge base.

\section{Consequences}

The literature confirmed that the outcome of the concept "health dialogue" was an improved health status (Roach et al. 2010; Street Jnr et al. 2009). However, the researchers were able to identify the consequences stemming from each of the three antecedents (positive attitude, sensitivity/respect and training) respectively.

- Positive attitude

Apositiveattitude towardsanequal healthcare relationshipleads toa deeperunderstanding of patients' problems (Butow et al. 2007), which in turn allows the healthcare provider to tap into the strengths of the patient population (Street Jnr et al. 2009). Patients who take an active role in their care, therefore displaying a positive attitude towards their own healthcare, achieve better health outcomes than patients who are not actively involved in their own care (Song et al. 2013; Roach et al. 2010). A health relationship grown from such a positive outlook leads to enhanced compliance (Hornby 2010), patient satisfaction (Royal College of General Practitioners 2014; Hardee et al. 2005), and a strengthened relationship between the patient and healthcare provider (Ko et al. 2011), as well as better recall of health messages (Gutheil \& Heyman 2005). 
- Sensitivity/Respect

Mutual sensitivity and respect towards reciprocal health communication lead to various positive outcomes, such as gaining an understanding of a health problem (Sanders Thompson et al. 2008), sustained behaviour change (Cross \& Bloomer 2010; Lee 2010), quality health communication (Norgaard et al. 2012), and achieving social justice (Schiavo 2014; Detmar et al. 2002). When sensitivity is shown towards the communication needs of specific patients, a positive health outcome is inevitable, especially when using combined health communication strategies, consolidated learning and recall in the context where behaviour is to be performed (McGilton et al. 2009; Hinchliff et al. 2005).

- Training

Training in communication skills for healthcare providers indirectly leads to improved health due to the increased quality of healthcare (Quinn et al. 2011; McGilton et al. 2009). Apart from the resultant empowerment of the healthcare provider (Savdie \& Chetley 2009), patient-centred healthcare and better cultural competency skills (Quinn et al. 2011) would lead to acknowledging the indigenous knowledge and skills patients bring to the health communication table.

\section{Stage ten: keying the empirical referents}

Empirical referents create the opportunity to measure the key characteristics (Walker \& Avant 2011). Each key characteristic therefore has its own specific empirical referent. Consequently, the characteristic "equal, symbiotic health relationship" has as its empirical referent "shared responsibility/decision-making". Any observable phenomena depicting the presence of shared responsibility/decision-making would thus be seen as the empirical referent for the key characteristic "equal, symbiotic health relationship". Such an example was provided in the discussion of the model case as a clearly demarcated role distribution between the healthcare provider and the patient, with subsequent responsibilities.

The characteristic "reciprocal health communication" has as its empirical referent a "health plan and mutual benefit" for both healthcare provider and patient. Again, the model case proposed such to be a healthcare plan with clearly identified actions and expected outcomes, whilst making it clear who is responsible for which action. Such a plan can be a formal written document, but is often rather an informal agreement between the healthcare provider and patient.

The third key characteristic, a "health message", has as its empirical referent a "context sensitive communication strategy". Again an example of such a communication strategy was provided in the model case as interpersonal communication between the healthcare provider and patient, in a language the patient understands, and in a manner that is acceptable to her. The message could also be packaged in other formats, such as illustrated in the borderline case, where a health information leaflet was used. 


\section{DISCUSSION}

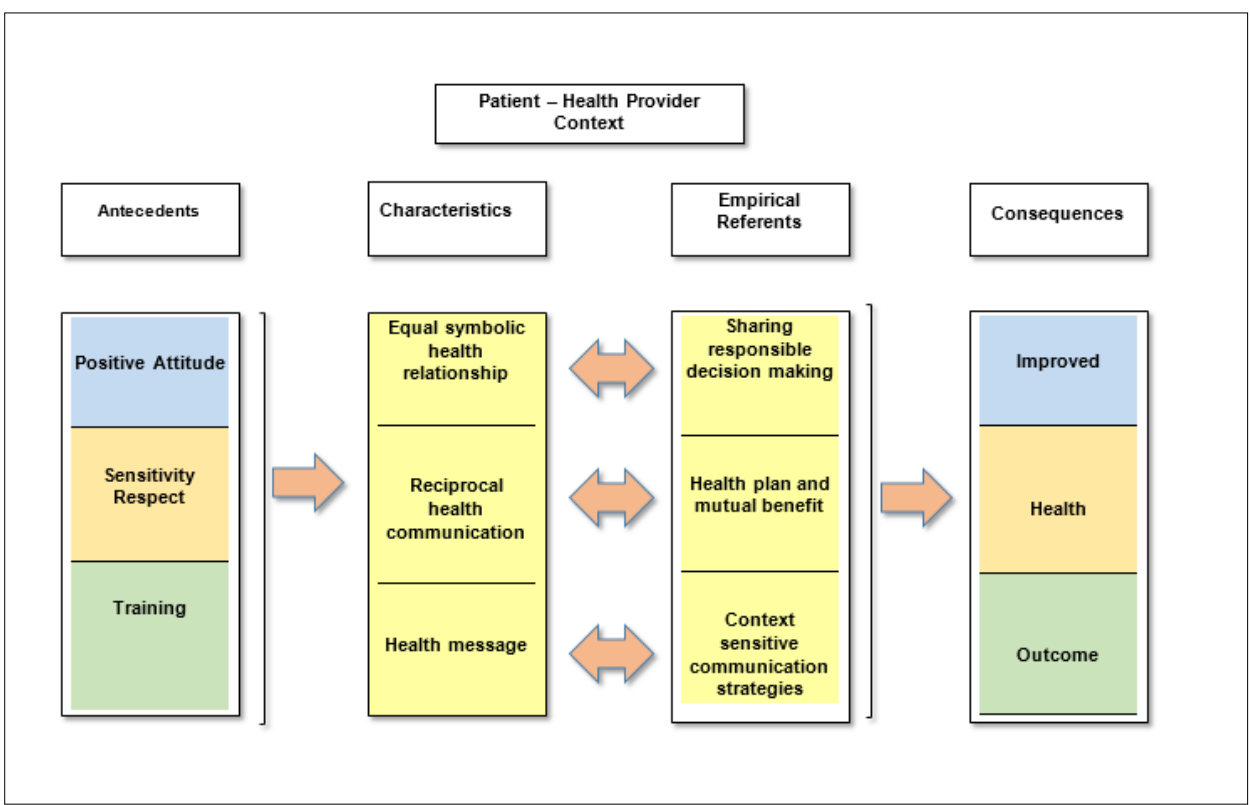

FIGURE 1: CONCEPTUAL MAP OF HEALTH DIALOGUE: ANTECEDENTS, CHARACTERISTICS, EMPIRICAL REFERENTS, CONSEQUENCES

Figure 1 depicts the conceptual map developed during the data analysis derived from Walker and Avant's (2011) framework. From the map, it becomes clear that all the antecedents need to be present prior to identifying key characteristics of the concept. Each key characteristic in turn becomes visual or measurable through a specific empirical referent. Although the overall consequence of the concept leads to an improved health outcome, examples discussed under "Consequences" illustrated more specifically how health could be improved, as aligned to a specific antecedent.

The linear presentation of the various health dialogue elements (antecedents, key characteristics, empirical referents and consequences) should not be confused with the iterative nature of the process that was followed to get to the conceptual map in Figure 1. Although these steps have been discussed sequentially, this does not necessarily depict the sequence in which the steps were executed. The thought processes during the mental construction of a concept follows an iterative process. In order to reach a more precise analysis, it is often necessary to make revisions in an earlier step because of insights arising from a later one.

The key characteristics and other elements of the concept "health dialogue" have a rigorous theoretical underpinning. The use of Walker and Avant's (2011) framework provided a useful methodology to guide and organise the concept analysis. Using a concept analysis as part of a research programme poses various advantages. In this 
article a concept clarification with a sound theoretical base was established, which promotes consistency whenever the concept was used. Understanding the underlying characteristics assisted in the development of an operational definition, which in turn could be used towards the development of a research instrument. Due to the measurable nature of these elements, the presence of each element can be tested. In practice it implies constructing an item using empirical referents to reflect each of the identified characteristics (Walker \& Avant 2011).

This opens new research directions in health dialogue, such as offering the opportunity for researchers to investigate the extent to which these elements occur during health dialogue between the healthcare provider and the patient. The measurement of the elements can in turn assist healthcare providers and policy makers to create a platform for a monitoring system for health dialogue, usable in different contexts. An example is an observational checklist operationalising antecedents and empirical referents, thus allowing the identification of health dialogue elements during health communication between healthcare providers and patients. The health dialogue elements identified with this concept analysis could act as a "golden standard" to strive towards during health dialogue. The saying rings true: "If you aim at nothing, you will surely hit the target". If we were to look again at Mrs N, presented in the model case, such an observational checklist could be used to observe the interaction between Mrs $\mathrm{N}$ and her healthcare provider, followed by feedback to these role players - in this way identifying elements to be strengthened, and ultimately improving health outcome.

\section{LIMITATIONS OF THE STUDY}

The aim of the current research was to present the results of a concept analysis of health dialogue; however, some limitations need to be noted. The empirical work reviewed was limited to material available in English from 2000-2013 and references were set as the limiter in the article search. Although material outside this period was excluded, no concept analysis on health dialogue was found up to date. Despite a rigorous analysis process, with two persons independently performing the data analysis, followed by consensus discussions, the presented concept analysis can never be seen as the final product. The tentative nature of the final product can be ascribed to two people not necessarily coming up with exactly the same characteristic due to the fast pace of knowledge generation and the influence of aspects, such as culture and society, on affecting change (Walker \& Avant 2011). It is further possible that researchers or healthcare providers, who have not previously been exposed to the participatory paradigm, could struggle to fully appreciate and apply their minds to the equal role the patient plays within health dialogue. Even though the data included depicted communication between adult patients and healthcare providers within an interpersonal, small group or mass communication context, it could potentially be a greater challenge to apply some elements within a mass communication context. 


\section{CONCLUSION}

The major challenge offered in this analysis concerns how healthcare providers can enrich their theoretical conceptualisation of health dialogue in order to improve the health outcomes of patients. The step-by-step process of Walker and Avant (2011) enabled the researchers in the conceptualisation of health dialogue.

Significant role players in taking the concept analysis forward are healthcare providers, such as nurses, policy makers and researchers. Nurses, often the backbone of health provision, play an important role in the health dialogue between the patient and the healthcare provider. The potential significance of the nurse's role in the health dialogue between the patient and the healthcare provider becomes even more meaningful when considering that patient participation leads to a significant improvement in personal and community health (Rensburg \& Krige 2011), especially seen within a participatory paradigm. Nurses therefore benefit from the vast number of studies on various aspects of health communication conducted and published in recognised journals and data bases worldwide (Nazione et al. 2013; Sakai 2013; Damasceno et al. 2012; Gessler et al. 2012; Sherman et al. 2011).

Policy makers need to operationalise the concept and construct a monitoring system for health dialogue that can be used in various settings. Such a monitoring system, reflecting the key elements, would offer healthcare providers a base to measure the concept in their work environment, and so encourage health communication. The empirical foundation provided by the set of key characteristics and other elements of the concept offers further research directions and could be tested by means of quantitative research. Acknowledging criticism of participatory approaches as making more sense theoretically and not necessarily translating to on-the-ground realities, researchers' assistance is needed in exploring the willingness of patients and healthcare providers to buy in to the elements of the concept presented.

Undertaking this concept analysis provided a step-by-step, structured approach to clarifying the potentially ambiguous concept of health dialogue. The analysis process produced an operational definition of health dialogue, which include the key characteristics of an equal, symbiotic healthcare relationship between the patient and the healthcare provider and reciprocal health communication towards reaching an identified goal via a health message. It also allowed for the identification of the antecedents, empirical referents and consequences of health dialogue and presented model, borderline and contrary cases.

\section{ACKNOWLEDGEMENTS}

The author would like to acknowledge Mrs Karin Venter who acted as a co-data analyst, Mrs Annamarie du Preez for assisting with literature searches, as well as Dr Marianne Viljoen for acting as the critical reader and language editor of this article. 


\section{Competing interests}

The author declares no financial or personal relationships(s) may inappropriately have influenced her in writing this article. The concept analysis forms part of a complex intervention funded by the South African National Research Foundation (Thuthuka Grant: 87892).

\section{REFERENCES}

Alligood, M.R. 2014. Nursing theorists and their work. (Eighth edition). St Louis, MO: Elsevier Mosby.

Bernhardt, J.M. 2004. Communication at the core of effective public health. American Journal of Public Health 94 (1): 2051-2053. https://doi.org/10.2105/AJPH.94.12.2051

Bousso, R.S., Poles, K. \& de Almeida Lopes Monteiro da Cruz, D. 2013. Nursing concepts and theories. Revista da Escola Enfermagem da USP 48(1): 141-145. https://doi. org/10.1590/S0080-623420140000100018

Bradley, L.J., Hendricks, B., Lock, R., Whiting P.P. \& Parr, G. 2011. E-mail communication: Issues for mental health counsellors. Journal of Mental Health Counseling 33(1): 67-79. https://doi.org/10.17744/mehc.33.1.05208025375v03r7

Briscoe, C. \& Aboud, F. 2012. Behaviour change communication targeting four health behaviours in developing countries: A review of change techniques. Social Science \& Medicine 75(4): 612-621. https://doi.org/10.1016/j.socscimed.2012.03.016

Butow, P., Harrison, J.D., Choy, E.T., Young, J.M., Spillane, A. \& Evans, A. 2007. Health professional and consumer views on involving breast cancer patients in the multidisciplinary discussion of their disease and treatment plan. American Cancer Society September: 1937-1943. https://doi.org/10.1002/cncr.23007

Castro, J.G., Jones, D.L., Lopez, M., Barradas, I. \& Weiss, S.M. 2010. Making the case for circumcision as a public health strategy: opening the dialogue. AIDS Patient Care \& STDs 24(6): 367-372. https://doi.org/10.1089/apc.2009.0353

Corcoran, N. 2013. Theories and models. In: Corcoran, N. (ed.) Communicating health: Strategies for health promotion. (Second edition). London: SAGE. https://doi. org/10.4135/9781526401588

Coulter, A., Parsons, S. \& Askham, J. 2008. Where are the patients in decision making about their own care? Health Systems and Policy Analysis, World Health Organisation: Geneva

Cowan, R. 2005. The dictionary of urbanism. Tisbury: Streetwise Press.

Cresswell, J. (ed.). 2010. Oxford dictionary of word origins. (Second edition). Oxford: Oxford University Press.

Cross, W.M. \& Bloomer, M.J. 2010. Extending boundaries: Clinical communication with culturally and linguistically diverse mental health clients and carers. International Journal of Mental Health Nursing 19: 268-277. https://doi.org/10.1111/j.14470349.2010.00667.x 
Damasceno, M.M.C., Zanett, M.L., De Carvalho, E.C., De Souza Teixeira, C.R., De Araújo, M.F.M. \& Alencar, A.M.P.G. 2012. Therapeutic communication between health workers and patients concerning diabetes mellitus care. Rev. Latino-Am. Enfermagem 20(4): 685-692. https://doi.org/10.1590/S0104-11692012000400008

Degni, F., Suominen, S., Essen, B., Ansari, W.E. \& Vehvilainen-Julkunen, K. 2012. Communication and cultural issues in providing reproductive health care to immigrant women: Health care providers' experiences in meeting Somali women living in Finland. Journal of Immigrant Minority Health 14: 330-343. https://doi. org/10.1007/s10903-011-9465-6

Detmar, S.M., Muller, M., Schornagel, J.H., Wever, L.D. \& Aaronson, N.K. 2002. Healthrelated quality-of-life assessments and patient-physician communication. The Patient-Physician Relationship 288(23): 3027-3035. https://doi.org/10.1001/ jama.288.23.3027

Donelle, L. \& Hoffman-Goetz, L. 2009. Functional health literacy and cancer care conversations in online forums for retired persons. Informatics for Health \& Social Care 34(1): 59-72. https://doi.org/10.1080/17538150902779535

DuBenske, L., Gustafson, D., Shaw, B. \& Cleary, J. 2010. Web-based cancer communication and decision making systems: Connecting patients, caregivers, and clinicians for improved health outcomes. Medical Decision Making 30(732): 732-744. https://doi. org/10.1177/0272989X10386382

Durant, N.H., Bartman, B., Person, S.D., Collins, F. \& Austin, S.B. 2009. Patient provider communication about the health effects of obesity. Patient Education and Counseling 75: 53-57. https://doi.org/10.1016/j.pec.2008.09.021

Gessler, N., Labhard, N.D., Stolt, P., Manga, E., Balo, J., Boffolo, A. \& Langewitz, W. 2012. The lesson of Monsieur Nouma: Effects of a culturally sensitive communication tool to improve health-seeking behavior in rural Cameroon. Patient Education and Counseling 87: 343-350. https://doi.org/10.1016/j.pec.2011.11.007

Goodall, K., Ward, P. \& Newman, L. 2010. Use of information and communication technology to provide health information: What do older migrants know, and what do they need to know? Quality in Primary Care 18: 27-32.

Gutheil, I. \& Heyman, J. 2005. Communication between older people and their health care agents: Results of an intervention. Health and Social Work 30(2): 107-116. https:// doi.org/10.1093/hsw/30.2.107

Han, J., Hawkins, R. \& Shaw, B. 2009. Unraveling uses and effects of an interactive health communication system. Journal of Broadcasting \& Electronic Media 53(1); 112-133. https://doi.org/10.1080/08838150802643787

Hardee, J.T., Platt, F.W. \& Kasper, I.K. 2005. Discussing health care costs with patients. Journal of General Internal Medicine 20: 666-669. https://doi.org/10.1111/j.15251497.2005.0125.x

Harvey, I. \& O'Brien, M. 2011. Addressing health disparities through patient education: The development of culturally-tailored health education materials at Puentes de Salud. Journal of Community Health Nursing 28: 181-189. https://doi.org/10.1080/ 07370016.2011 .614827 
Hinchliff, S., Gott, M. \& Galena, E. 2005. 'I daresay I might find it embarrassing': General practitioners' perspectives on discussing sexual health issues with lesbian and gay patients. Health and Social Care in the Community 13(4): 345-353. https://doi. org/10.1111/j.1365-2524.2005.00566.x

Hornby, S. 2010. Oxford advanced learner's dictionary of current English. (Eighth edition). Oxford: Oxford University Press.

Kalbfleisch, P.J. 2009. Effective health communication in native populations in North America. Journal of Language and Social Psychology 28(2): 158-173. https://doi. org/10.1177/0261927X08330607

Kemppainen, V., Tossavainen, K. \& Turunen, H. 2012. Nurses' roles in health promotion practice: An integrative review. Health Promotion International 28(4): 490-501. https://doi.org/10.1093/heapro/das034

Ko, L., Campbell, M.K., Lewis, M.A., Earp, J. \& DeVellis, B. 2011. Information processes mediate the effect of a health communication intervention on fruit and vegetable consumption. Journal of Health Communication 16: 282-299. https://doi.org/10.108 0/10810730.2010.532294

Kreps, G. \& Sivaram, R. 2008. Strategic health communication across the continuum of breast cancer care in limited-resource countries. American Cancer Society 113(8): 2331-2337. https://doi.org/10.1002/cncr.23832

Lapinski, M.K.R.L.M., Peterson, M., Peterson, A. \& Klein, K.A. 2009. Prevention options for positives: The effects of a health communication intervention for men who have sex with men living with HIVIAIDS. Health Communication 24: 562-571. https://doi. org/10.1080/10410230903104947

Lee, J.S. 2010. Channels of health communications used among Korean and Asian Indian older adults. Social Work in Health Care 49: 165-175. https://doi. org/10.1080/00981380903157997

Longtin, Y., Sax, H., Leape, L.L., Sheridan, S.E., Donaldson, L. \& Pittet, D. 2010. Patient participation: Current knowledge and applicability to patient safety. Mayo Clinic Proceedings 85(1): 53-62. https://doi.org/10.4065/mcp.2009.0248

Malta, M., Todd, C.S., Stibich, M.A., Garcia, T., Pacheco, D. \& Bastos, F.I. 2010. Patientprovider communication and reproductive health among HIV-positive women in Rio de Janeiro, Brazil. Patient Education and Counseling 81: 476-482. https://doi. org/10.1016/j.pec.2010.09.013

McGilton, K.S., Boscart, V., Fox, M., Sidani, S., Rochon, E. \& Sorin-Peters, R. 2009. A systematic review of the effectiveness of communication interventions for health care providers caring for patients in residential care settings. Worldviews on Evidence-based Nursing Third Quarter: 149-159. https://doi.org/10.1111/j.17416787.2009.00155.x

McMillan, S.J., Avery, E.J. \& Macias, W. 2008. From have nots to watch dogs: Understanding internet health communication behaviors of online senior citizens. Information, Communication \& Society 11(5): 675-697. https://doi. org/10.1080/13691180802126745

Munodwafa, D. 2008. Communication: concepts, practices and challenges. Health Education Research 23(3): 369-370. https://doi.org/10.1093/her/cyn024 
Nazione, S., Pace, K., Russell, J. \& Silk, K. 2013. A 10-year content analysis of original research articles published in 'Health Communication' and 'Journal of Health Communication' (2000-2009). Journal of Health Communication 18: 223-240. https://doi.org/10.1080/10810730.2012.688253

Neuhauser, L., Rothchild, B., Graham, C., Ivey, S.L. \& Konishi, S. 2009. Participatory design of mass health communication in three languages for seniors and people with disabilities on Medicaid. Research and Practice 99(12): 2188-2195. https://doi. org/10.2105/AJPH.2008.155648

Norgaard, B., Kofoed, P., Kyvik, K.O. \& Ammentorp, J. 2012. Communication skills training for health care professionals improves the adult orthopedic patient's experience of quality of care. Scandinavian Journal of Caring Sciences 26: 698-704. https://doi. org/10.1111/j.1471-6712.2012.00982.x

Nuopponen, N. 2010. Methods of concept analysis - a comparative study. Language for Special Purposes, Professional Communication, Knowledge Management, and Cognition Journal 1(1): 1-15.

Osterlund, E.E., Klang, B., Larsson, K., Ehrenberg, A. \& Fossum, B. 2009. Communication and self-management education at nurse-led COPD clinics in primary health care. Patient Education and Counseling 77: 209-217.

Petts, J. \& Niemeyer, S. 2004. Health risk communication and amplification: Learning from the MMR vaccination controversy. Health, Risk \& Society 6(1): 7-23. https://doi.org/ $10.1080 / 13698570410001678284$

Quinn, G.P., Jimenez, J., Meade, C.D., Munoz-Antonia, T., Gwede, C.K., Castro, E., Vadaparampil, S.T., Simmons, V.N., Mclntyre, J., Crocker, T.T. \& Brandon, T.H. 2011. Enhancing oncology health care providers' sensitivity to cultural communication to reduce cancer disparities: a pilot study. Journal of Cancer Education 26: 322-325. https://doi.org/10.1007/s13187-011-0223-1

Redsell, S.A., Bedford, H., Siriwardena, A.N., Collier, J. \& Atkinson, P. 2010. Health visitors' perception of their role in the universal childhood immunisation programme and their communication strategies with parents. Primary Health Care Research \& Development 11: 51-60. https://doi.org/10.1017/S1463423609990284

Rensburg, R. \& Krige, D. 2011. Aspects of health communication. In: Tomaselli, K. \& Chasi, C. (eds). Development and public health communication. Cape Town: Pearson Education.

Rimer, B.K. \& Kreuter, M.W. 2006. Advancing tailored health communication. Journal of Communication 56: 184-201. https://doi.org/10.1111/j.1460-2466.2006.00289.x

Roach, P., Klindukhova, O., Saha, C., Hudson, B., Cantrell, M. \& Marrero, D. 2010. Project RedCar: Cardiovascular disease risk communication for people with Type 2 diabetes combining the power of electronic health records and computer-based multimedia technology. Diabetes Spectrum 23(3): 155-160. https://doi.org/10.2337/ diaspect.23.3.155

Royal College of General Practitioners. 2014. Patient participation groups. [Online]. Available at: www.rcgp.org.uk/-/media/Files/.../RCGPNI-Patient-ParticipationBooklet [Accessed on 15 March 2019]. 
Rule, P. 2011. Bakhtin and Freire: Dialogue, dialectic and boundary learning. Educational Philosophy \& Theory 43(9): 924-942. https://doi.org/10.1111/j.14695812.2009.00606.x

Sakai, Y. 2013. The role of readability in effective health communication: An experiment using a Japanese health information text on chronic suppurative otitis media. Health Information and Libraries Journal 30: 220-231. https://doi.org/10.1111/hir.12022

Sanders Thompson, V.L., Cavazos-Rehg, P.A., Jupka, K., Caito, N., Gratzke, J., Tate, K.Y., Deshpande, A. \& Kreuter, M.W. 2008. Evidential preferences: Cultural appropriateness strategies in health communications. Health Education Research 23(3): 549-559. https://doi.org/10.1093/her/cym029

Savdie, A. \& Chetley, A. 2009. Sexual-health communication across and within cultures: The Clown Project, Guatemala. Development in Practice 19(4-5): 560-572. https:// doi.org/10.1080/09614520902866447

Schiavo, R. 2014. Health communication from theory to practice. (Second edition). San Francisco: Jossey-Bass.

Schöpf, A.C., Puy, L., Schmidt, E. \& Farin, E. 2017. Physicians' reactions to patients taking a position: Sequence analysis of admission interviews in orthopaedic rehabilitation. Health Communication 32: 703-713. https://doi.org/10.1080/10410236.2016.1168002

Sherman, D., Uskul, A. \& Updegraff, J. 2011. The role of the self in responses to health communications: A cultural perspective. Self and Identity 10(3): 284-294. https://doi. org/10.1080/15298868.2010.517029

Song, L., Bensen, J.T., Zimmer, C., Sleath, B., Blackard, B., Fontham, E., Su, L.J., Brennan, C.S., Mohler, J.L. \& Mishel, M. 2013. Patient-health care provider communication among patients with newly diagnosed prostate cancer: Findings from a populationbased survey. Patient Education and Counselling $91:$ 79-84. https://doi.org/10.1016/j. pec.2012.12.002

Stevenson, A. (ed.). 2010. Oxford dictionary of English. (Third edition). Oxford: Oxford University Press.

Stevenson, A. \& Waite, M. (eds). 2011. Concise Oxford English dictionary. (Twelfth edition). Oxford: Oxford University Press.

Street Jnr, R., Makoul, G., Arora, N. \& Epstein, R. 2009. How does communication heal? Pathways linking clinician-patient communication to health outcomes. Patient Education and Counselling 74: 295-301. https://doi.org/10.1016/j.pec.2008.11.015

Suggs, S.L. \& Mclntyre, C. 2009. 'Are we there yet?' An examination of online tailored health communication. Health, Education \& Behavior 36(2): 278-288. https://doi. org/10.1177/1090198107303309

Taylor, S.P., Nicolle, C. \& Maguire M. 2013. Cross-cultural communication barriers in health care. Art and Science Research 27(31): 35-43. https://doi.org/10.7748/ ns2013.04.27.31.35.e7040

Tomaselli, K. 2011. Paradigm interaction: Some notes on development and communication. In: Tomaselli, K. \& Chasi, C. (eds). Development and public health communication. Cape Town: Pearson Education. 
Tubbs, S., Moss, S. \& Papastefanou, N. 2012. Human communication: Principles and contexts. London: McGraw-Hill.

Vahabi, M. 2007. The impact of health communication on health-related decision making: A review of evidence. Health Education 107(1): 27-41. https://doi. org/10.1108/09654280710716860

Varma, D.S., Khan, M.E. \& Hazra, A. 2010. Increasing institutional delivery and access to emergency obstetric care services in rural Uttar Pradesh. The Journal of Family Welfare 56 (Special Issue): 23-30.

Vivian, B.G. \& Wilcox, J.R. 2000. Compliance communication in home health care: A mutually reciprocal process. Qualitative Health Research 10: 103-116. https://doi. org/10.1177/104973200129118273

Walker, L.O. \& Avant, K.C. 2011. Strategies for theory construction in nursing. Boston: Pearson.

White, K. 2006. The Sage dictionary of health and society. London: Sage. https://doi. org/10.4135/9781446215159 